\title{
Synthesis of Triazoles with Potential Antileishmanial Activity by Click Chemistry
}

\author{
Cíntia Maria Carneiro Franco Lima (PG)*, Maurício Moraes Victor (PQ).
}

Organic Chemistry Department, Chemistry Institute, Federal University of Bahia (UFBA), CEP: 40170-290

*cinthola86@hotmail.com

Keywords: Click Chemistry, Triazoles, Organic Synthesis.

\section{INTRODUCTION}

Click Chemistry is an organic synthesis procedure, which follows the principles of green chemistry, being introduced by Sharpless in 2001. ${ }^{1}$ The most prominent chemical reaction using this procedure is the $\mathrm{Cu}(\mathrm{I})$-catalyzed 1,3-dipolar azide-alkyne cycloaddition (CuAAC), leading to 1,2,3 triazoles. ${ }^{2}$ From this context, our approach aims to synthesize substances with potential antileishmanial activity similar as presented by Silva, ${ }^{3}$ using Click Chemistry but with innovation as the insertion of the triazole unit is presented below:

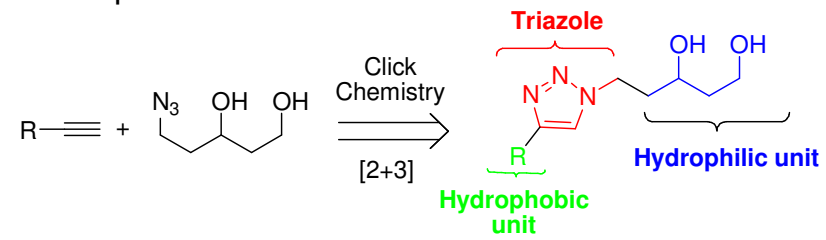

Scheme 1. General structure of bioactive triazoles.

\section{RESULTS AND DISCUSSION}

Primarily, we did a test reaction in order to ascertain the efficiency of the Click reaction with similar procedure described by Nierengarten ${ }^{4}$ in 2008 . The alcohol-bistriazole (II) was produced with $28 \%$ yield as a white solid.

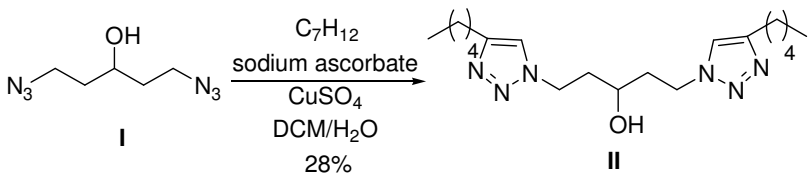

Scheme 2. Synthesis of the alcohol-bistriazole II.

Our strategy to synthesize the alcohol-triazole is shown below:
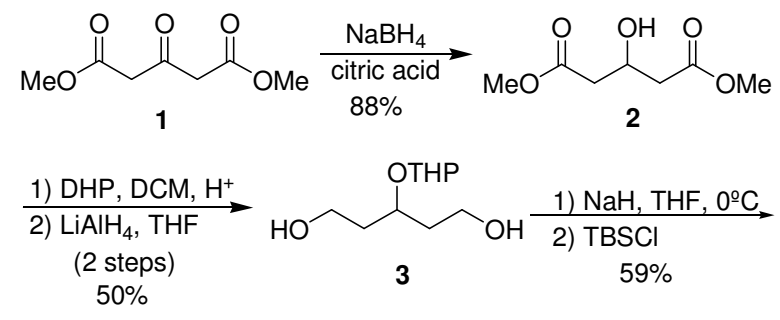

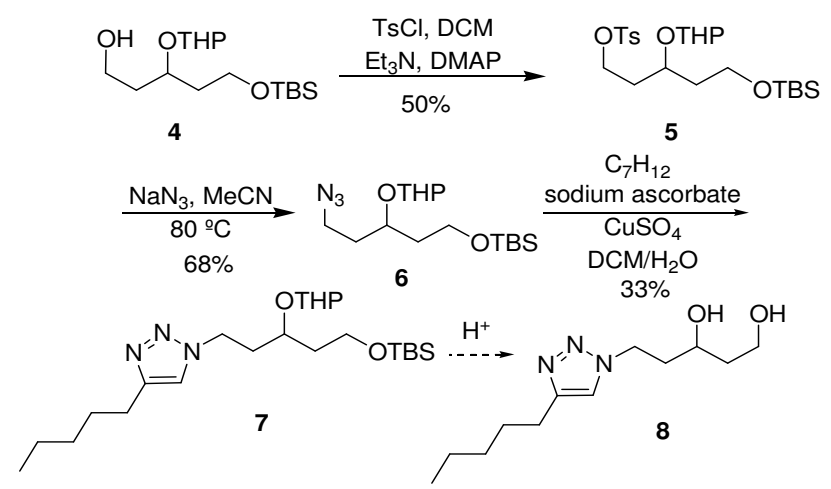

Scheme 3. Synthetic route to hydroxyl-triazoles.

The synthesis began by chemoselective reduction of dimethyl 3-oxo-glutarate 1 using $\mathrm{NaBH}_{4}$ and citric acid to afford dimethyl 3-hydroxy-glutarate 2 . The sequence of preparation required protection of secondary alcohol and reduction of esters moieties, performed with DHP on acid catalysis (PTSA) followed by treatment of crude with $\mathrm{LiAlH}_{4}$ in THF, respectively. The symmetrical diol $\mathbf{3}$, obtained in $50 \%$ for two steps, was monoprotected with TBSCI, leading to the alcohol 4. The next stage was the hydroxyl protection with $\mathrm{TsCl}$ in the presence of DMAP and $\mathrm{Et}_{3} \mathrm{~N}$ in DCM, leading to the formation of fully protected $\mathbf{5}$. Azido treatment in hot acetonitrile yielded $\mathbf{6}$. The cycloaddition of azide compound $\mathbf{6}$ with hept-1-yno in heterogeneous mixture of DCM and water with use of $\mathrm{CuSO}_{4}$ as catalyst produced the alcohol-triazole 7 in $33 \%$.

\section{CONCLUSION}

We synthesized the alcohol-triazole 7 from dimethyl 3-oxo-glutarate in 8 steps, using Click Chemistry procedure as key step in cycloaddition between azide 6 and hept-1-yne.

\section{ACKNOWLEDGEMENTS}

GPSQ for chemical support and Capes for the scholarship.

\section{REFERENCES}

SHARPLESS, K.B; et al. Angew. Chem. 2001, 40, 2004-2021.

2 KAPPE, C.O; van der EYCKEN, E. Chem. Soc. Rev. 2009, 39,1280-1290.

${ }^{3}$ SILVA, A.D; et al. Chem. Biol. Drug Des. 2010, 75, 233-235.

${ }^{4}$ NIERENGARTEN, J.F; et al. Tetrahedron Lett. 2008, 49, 40634066. 